\title{
Acumuladores de animais na perspectiva da promoção e da vigilância em saúde
}

\author{
Animal accumulators from the perspective of health promotion and \\ surveillance
}

Claudio Manuel Rodrigues

'Centro de Desenvolvimento Tecnológico em Saúde, Fundação Oswaldo Cruz (FIOCRUZ) - Rio de Janeiro (RJ), Brasil.

DOI: https://dx.doi.org/10.7322/abcshs.v44i3.1394

\section{RESUMO}

A acumulação de animais é considerada um fenômeno complexo que, apesar de já ser reconhecido no universo acadêmico, ainda é de difícil solução para a gestão da saúde. Os estudos a respeito de acumulação, principalmente de animais, são incipientes no Brasil. Este artigo de revisão da literatura tem por objetivo alertar a respeito desta complexa morbidade, cada vez mais comum às aglomerações urbanas, indicando ações de promoção e de vigilância em saúde que permitam garantir a saúde dos animais, do acumulador e da coletividade a qual ele pertença. Sugere-se que uma nova abordagem em relação ao distúrbio de acumulação de animais possa combater a pouca visibilidade - inclusive acadêmica - demonstrada na revisão da literatura, ampliando o investimento em intervenções específicas que possam explicitar esse importante problema de saúde pública no Brasil.

Palavras-chave: Transtorno de acumulação; autonegligência; animais de estimação; Vigilância em Saúde.

\begin{abstract}
Animal accumulation is considered a complex phenomenon that, although recognized in the academic universe, is still difficult to solve for health management. Studies on accumulation, mainly of animals, are incipient in Brazil. This literature review article aims to warn about this complex morbidity, which is increasingly common to urban agglomerations, indicating health promotion and surveillance actions to ensure the health of animals, the accumulator and the community to which it belongs. It is suggested that a new approach to animal accumulation disorder may counteract the poor - including academic - visibility demonstrated in the literature review, increasing investment in specific interventions that may explain this important public health problem in Brazil.
\end{abstract}

Keywords: Hoarding disorder; self-neglect; pets; Public health surveillance. 


\section{INTRODUÇÃO}

$\mathrm{O}$ transtorno de acumulação animal, na língua inglesa denominada Animal Hoarding Disorder (AHD), também conhecida como Síndrome de Noé1, é um fenômeno complexo que levanta questões relacionadas à saúde pública e aos meios jurídicos ${ }^{2}$. Algumas características indicativas do comportamento de um acumulador de animais podem ser observadas, como a reunião de um grande número de animais, normalmente recolhidos das ruas; o apego demasiado aos animais tutelados; e o não atendimento às necessidades básicas de bem-estar animal, não havendo garantia à integridade física, ao atendimento médico-veterinário e ao acesso adequado à alimentação e à higiene. Entretanto, por se tratar de uma desordem da saúde mental, o acumulador não tem a capacidade de entender e reconhecer a crueldade e o sofrimento imputado aos animais confinados, chegando a situações extremas de negar eventuais óbitos dos que se encontram sob tutela ${ }^{3,4,5}$.

Em geral, acumuladores animais não têm senso crítico da anormalidade patológica de sua atitude, porém, sem dúvida, seu comportamento provoca reações angustiantes de familiares, vizinhos e amigos, sendo importante motivador de solicitação de intervenção pelo sistema de saúde local, de atividades de urgência médico-veterinárias, da ordem pública e dos órgãos de gestão do meio ambiente, além de demandas jurídicas devido aos comportamentos desviantes de personalidade $\mathrm{e}^{6,7,8}$.

Uma revisão a respeito do assunto identificou diferenças entre o acúmulo de animais e o acúmulo contumaz de objetos, com predominância de mulheres em avançada idade, que apresentam sintomatologia mais tardia para o hábito de acumulação, vivendo em condições sanitárias mais precárias e com maior aspecto de desordem, entretanto com menor variedade de itens acumulados entre aqueles diagnosticados como acumuladores animais 9

Os estudos a respeito de acumulação, principalmente de animais, são incipientes no Brasil, havendo poucos autores que se debruçam sobre a temática e, por conseguinte, existindo pouco material que reforce intervenções específicas para, não só a adequada assistência à população considerada vulnerável, mas também sustentar uma política de saúde conceitualmente ampliada que abranja a sociedade e os animais a ela atrelados ${ }^{10}$.

Sendo assim, o objetivo desta revisão foi alertar a respeito dessa morbidade, cada vez mais comum aos aglomerados urbanos do Brasil, e desenvolver sugestões para embasar uma ação multidisciplinar da promoção e da vigilância em saúde em situações de necessária intervenção pelo poder público.

\section{MÉTODO}

Revisão crítica do tipo narrativa da literatura. Para reconhecer o estado da arte a respeito do tema acumulação de animais, sob a lógica da promoção e prevenção em saúde, foi realizada uma revisão de literatura em três bases de dados de indubitável importância para temas relacionados à saúde pública: Web of Science, Public Medline (PubMed) e Biblioteca Virtual em Saúde (BVS). Para tal, utilizou-se termos de busca nas línguas portuguesa, espanhola e inglesa e recuperou-se em uma busca geral (Título, Resumo e Assunto/Descritores) e em uma busca específica por Título - o conteúdo de publicações entre os anos de 2014 e 2019 , indicando também o quantitativo de manuscritos de acesso aberto disponibilizados em cada uma das plataformas digitais. Também se verificou o ano de publicação dos manuscritos que mais se aproximavam do tema de estudo, selecionados através do uso dos termos de busca que mais o expressaram. Os resultados foram expressos nos Tabelas 1, 2 e 3.

\section{RESULTADOS E DISCUSSÃO}

Dentre os termos de busca que melhor sintetizaram a recuperação de manuscritos que permeavam a temática de acumulação de

Tabela 1: Bases de dados consultadas e manuscritos recuperados na busca geral.

\begin{tabular}{|c|c|c|c|}
\hline \multirow{2}{*}{ Termos de busca } & \multicolumn{3}{|c|}{ Bases de dados consultadas* } \\
\hline & Web of Science & PubMed & BVS \\
\hline Hoarding & $959(243)$ & $470(156)$ & $1385(820)$ \\
\hline Acumulação & $2(0)$ & $1(1)$ & $804(654)$ \\
\hline Colecionismo & 0 & 0 & $310(269)$ \\
\hline Acumulación & $34(12)$ & $5(2)$ & 5002 (1626) \\
\hline "Hoarding disorder" & $220(62)$ & $189(65)$ & 299 (265) \\
\hline $\begin{array}{l}\text { "Transtorno de } \\
\text { acumulação" }\end{array}$ & 0 & 0 & $213(191)$ \\
\hline Entesouramento & 0 & 0 & $65(56)$ \\
\hline $\begin{array}{l}\text { "Hoarding disorder" } \\
\text { "Animal" }\end{array}$ & $9(4)$ & $10(3)$ & $15(15)$ \\
\hline $\begin{array}{l}\text { "Transtorno de } \\
\text { acumulação" "Animal" }\end{array}$ & 0 & 0 & $10(10)$ \\
\hline "Compulsive hoarding" & $40(7)$ & $24(6)$ & $131(78)$ \\
\hline $\begin{array}{l}\text { "Acumulação } \\
\text { compulsiva" }\end{array}$ & 0 & 0 & $2(2)$ \\
\hline $\begin{array}{l}\text { "Acumulación } \\
\text { compulsiva" }\end{array}$ & 0 & 0 & $2(1)$ \\
\hline $\begin{array}{l}\text { "Colecionismo } \\
\text { compulsivo" }\end{array}$ & 0 & $7(2)$ & $1(1)$ \\
\hline $\begin{array}{l}\text { "Compulsive hoarding" } \\
\text { "Animal" }\end{array}$ & $1(0)$ & 0 & $6(5)$ \\
\hline "Animal hoarding" & $20(2)$ & $13(2)$ & $16(15)$ \\
\hline $\begin{array}{l}\text { "Acumulação de } \\
\text { animais" }\end{array}$ & 0 & 0 & $2(2)$ \\
\hline "Acumulación animal" & 0 & $2(2)$ & 0 \\
\hline $\begin{array}{l}\text { "Acumulación de } \\
\text { animales" }\end{array}$ & 0 & 0 & $1(1)$ \\
\hline "Síndrome de Noé" & 0 & 0 & 0 \\
\hline "Noah syndrome" & $1(0)$ & $6(2)$ & $1(1)$ \\
\hline $\begin{array}{l}\text { "Síndrome de } \\
\text { Diógenes" }\end{array}$ & 0 & 0 & $224(190)$ \\
\hline "Diogenes Syndrome" & $29(2)$ & $21(3)$ & $105(40)$ \\
\hline $\begin{array}{l}\text { "Síndrome de } \\
\text { Diógenes" "Animal" }\end{array}$ & 0 & 0 & $9(9)$ \\
\hline $\begin{array}{l}\text { "Diogenes Syndrome" } \\
\text { "Animal" }\end{array}$ & $1(0)$ & $2(1)$ & $2(2)$ \\
\hline
\end{tabular}

${ }^{*} X X(Y Y)$ sendo $X X=$ busca geral e $Y Y=$ acesso aberto. 
animais, os que tiveram maior relevância foram [hoarding disorder AND animal], [animal hoarding], [transtorno de acumulação AND animal] e [síndrome de Diógenes AND animal]. A representação de seus quantitativos, assim como de todos os descritores utilizados, estão expressos na Tabela 1, estando identificados com a fonte em negrito aqueles resultados que considerou-se de maior relevância. O destaque fica para o número de publicações em língua inglesa sobre o tema, assim como a importante participação da BVS nesse quantitativo.

Além dos termos de busca acima citados, foram incluídos outros como de importância secundária para a temática em questão. Observou-se que o termo [síndrome de Noé] não tem qualquer citação nas línguas portuguesa e espanhola, mas sua tradução para a língua inglesa [Noah syndrome] possui seis observações na base de dados PubMed entre 2014 e 2019. Por isso também fizemos questão de tê-lo entre os descritores desse estudo. Outras associações entre termos de busca mereceram nossa atenção, caso de [compulsive hoarding AND animal], também com seis observações dentre aqueles indexados na BVS.

Desses termos de busca, elegeu-se as quatro combinações que consideramos de maior impacto, por terem maior contingente de observações em manuscritos indexados e representarem melhor a problemática da acumulação de animais, para figurarem em conjunto com na análise da periodicidade de publicação expressada pela Tabela 2. Dessa forma, procurou-se repercutir a recente produção de relevância acadêmica com base nas fontes de indexação utilizadas, com destaque para o ano de 2017 como o de maior produção, seguido dos anos de 2018 e 2014.

$\mathrm{Na}$ Tabela 3 procurou-se identificar a importância do tema em questão, buscando por manuscritos que possuíam os termos de busca e suas combinações em seu título. O destaque ficou por conta daqueles manuscritos que marcaram presença nas três plataformas digitais se utilizando da associação entre os termos de busca em língua inglesa: [animal hoarding] com 16 aparições em títulos de manuscritos indexados na Web of Science e [hoarding disorder AND animal] com cinco observações na base de dados PubMed.

Assim como na Tabela 1, na Tabela 3 procurou-se comparar o quantitativo de manuscritos depositados nas referidas bases de dados com o quantitativo disponível para acesso aberto, com destaque positivo para a BVS, que além de depositar maior número de publicações, mantém o maior acervo de manuscritos de acesso aberto dentre as três plataformas digitais utilizadas.

Desse conteúdo, com base na relevância acadêmica e na pertinência para com o estudo em questão, associado às buscas por literatura cinzenta ou não indexada (manuais, livros, resumos de anais, publicações em sítios eletrônicos, etc.) na plataforma digital Google Scholar, que foram considerados muito importantes para contextualização da temática frente às demandas atuais da sociedade, selecionou-se as referências utilizadas na organização desse estudo.

Tabela 2: Bases de dados consultadas e manuscritos recuperados por ano de publicação.

\begin{tabular}{|c|c|c|c|c|c|}
\hline \multirow{2}{*}{ Termos de busca } & & \multicolumn{3}{|c|}{ Bases de dados consultadas* } & \multirow{2}{*}{ Tota } \\
\hline & & Web of Science & PubMed & BVS & \\
\hline \multirow{6}{*}{ "Hoarding disorder" "Animal" } & 2014 & 2 & 2 & 3 & 7 \\
\hline & 2015 & 2 & 1 & 1 & 4 \\
\hline & 2016 & 1 & 2 & 3 & 6 \\
\hline & 2017 & 3 & 3 & 6 & 12 \\
\hline & 2018 & 1 & 2 & 2 & 5 \\
\hline & 2019 & 0 & 0 & 0 & 0 \\
\hline \multirow{6}{*}{ "Transtorno de acumulação" "Animal" } & 2014 & 0 & 0 & 0 & 0 \\
\hline & 2015 & 0 & 0 & 1 & 1 \\
\hline & 2016 & 0 & 0 & 3 & 3 \\
\hline & 2017 & 0 & 0 & 6 & 6 \\
\hline & 2018 & 0 & 0 & 0 & 0 \\
\hline & 2019 & 0 & 0 & 0 & 0 \\
\hline \multirow{6}{*}{ "Animal hoarding" } & 2014 & 8 & 4 & 5 & 17 \\
\hline & 2015 & 2 & 2 & 2 & 6 \\
\hline & 2016 & 2 & 0 & 0 & 2 \\
\hline & 2017 & 5 & 2 & 4 & 11 \\
\hline & 2018 & 3 & 5 & 5 & 13 \\
\hline & 2019 & 0 & 0 & 0 & 0 \\
\hline \multirow{6}{*}{ "Síndrome de Diógenes" "Animal" } & 2014 & 0 & 0 & 0 & 0 \\
\hline & 2015 & 0 & 0 & 1 & 1 \\
\hline & 2016 & 0 & 0 & 3 & 3 \\
\hline & 2017 & 0 & 0 & 5 & 5 \\
\hline & 2018 & 0 & 0 & 0 & 0 \\
\hline & 2019 & 0 & 0 & 0 & 0 \\
\hline
\end{tabular}

${ }^{*} X X=$ quantidade de publicações por ano em busca geral. 


\section{Transtorno de acumulação animal: aspectos gerais}

Estudos iniciais sobre acumuladores de animais descrevem esses indivíduos como proprietários de um grande contingente de animais que mantinham determinadas características em comum: a baixa renda, ser sozinho e morar em condições insalubres, sendo impossível manter as condições hígidas adequadas para a criação dos animais. Além disso, um forte sentimento de apego impede que sejam realizadas adoções por outrem ou que se permitam resgates por organizações da sociedade civil, levando a situações em que o bem-estar e a saúde dos animais estão seriamente ameaçados ${ }^{11}$.

Patronek ${ }^{4}$ abre discussão a respeito de critérios diagnósticos para indivíduos que se denominava de "colecionadores de animais", apresentando essas condições como de importância para a saúde coletiva. Nesse estudo, o pesquisador os caracteriza como indivíduos que acumulam grande número de animais, a ponto de não saberem ao certo quantos estão sob sua tutela; que não fornecem condições mínimas de qualidade de vida e de saúde aos animais; e que são incapazes de perceberem o estado de deterioração

Tabela 3: Bases de dados consultadas e manuscritos recuperados na busca por títulos.

\begin{tabular}{|c|c|c|c|}
\hline \multirow{2}{*}{ Termos de busca } & \multicolumn{3}{|c|}{ Bases de dados consultadas* } \\
\hline & Web of Science & PubMed & BVS \\
\hline Hoarding & $411(96)$ & $20(2)$ & $240(211)$ \\
\hline Acumulação & 0 & 0 & $24(21)$ \\
\hline Colecionismo & 0 & 0 & $1(0)$ \\
\hline Acumulación & 0 & 0 & $36(25)$ \\
\hline "Hoarding disorder" & $112(33)$ & $86(35)$ & $91(85)$ \\
\hline $\begin{array}{l}\text { "Transtorno de } \\
\text { acumulação" }\end{array}$ & 0 & 0 & $5(4)$ \\
\hline Entesouramento & 0 & 0 & $1(1)$ \\
\hline $\begin{array}{l}\text { "Hoarding disorder" } \\
\text { "Animal" }\end{array}$ & $2(1)$ & $5(2)$ & $3(3)$ \\
\hline $\begin{array}{l}\text { "Transtorno de } \\
\text { acumulação" "Animal" }\end{array}$ & 0 & 0 & $1(1)$ \\
\hline "Compulsive hoarding" & $11(1)$ & $4(2)$ & $7(5)$ \\
\hline "Acumulação compulsiva" & 0 & 0 & $2(2)$ \\
\hline "Acumulación compulsiva" & 0 & 0 & $2(1)$ \\
\hline "Colecionismo compulsivo" & 0 & 0 & 0 \\
\hline $\begin{array}{l}\text { "Compulsive hoarding" } \\
\text { "Animal" }\end{array}$ & $1(0)$ & 0 & 0 \\
\hline "Animal hoarding" & $16(1)$ & $10(1)$ & $11(10)$ \\
\hline "Acumulação de animais" & 0 & 0 & $1(1)$ \\
\hline "Acumulación animal" & 0 & 0 & 0 \\
\hline "Acumulación de animales" & 0 & 0 & $1(1)$ \\
\hline "Síndrome de Noé" & 0 & 0 & 0 \\
\hline "Noah syndrome" & $1(0)$ & 0 & $1(1)$ \\
\hline "Síndrome de Diógenes" & 0 & 0 & $2(2)$ \\
\hline "Diogenes Syndrome" & $17(1)$ & $19(3)$ & $21(19)$ \\
\hline $\begin{array}{l}\text { "Síndrome de Diógenes" } \\
\text { "Animal" }\end{array}$ & 0 & 0 & 0 \\
\hline $\begin{array}{l}\text { "Diogenes Syndrome" } \\
\text { "Animal" }\end{array}$ & $1(0)$ & $1(0)$ & $1(1)$ \\
\hline
\end{tabular}

${ }^{*} X X(Y Y)$ sendo $X X=$ busca no título e $Y Y=$ acesso aberto. do ambiente e da saúde e do bem-estar de si próprios, de sua família e dos animais tutelados ${ }^{4,9}$.

No decorrer do tempo, especialistas em saúde mental buscaram definir a etiopatogenia e demais aspectos nosológicos da acumulação de animais acrescentando um novo critério que diz respeito à incapacidade do indivíduo reconhecer as consequências negativas em decorrência de seu comportamento acumulador ${ }^{9,10}$. Entretanto, só definiram a acumulação compulsiva como um transtorno mental na $5^{\mathrm{a}}$ edição do Diagnostic and Statistical Manual of Mental Disorders (DSM-5) ${ }^{12}$ em 2013 e, dessa forma, a descrição médica dos sintomas permanece em contínuo aprimoramento, sendo foco de amplo debate e $^{3,4,9,10}$.

Anteriormente considerado como um possível sintoma de transtorno obsessivo-compulsivo (TOC) ou como um transtorno de personalidade obsessivo-compulsivo (OCPD), nessa mais recente edição o transtorno de acumulação ganhou status de entidade nosográfica individualizada, intitulada como 'Hoarding Disorder' (HD) e incluída na seção 'Transtorno ObsessivoCompulsivo e Transtornos Relacionados'. A acumulação animal, tratada com 'Animal Hoarding' (AH), foi caracterizada como uma manifestação especial de transtorno de acumulação ${ }^{12}$.

Os acumuladores animais frequentemente negligenciam sua própria saúde e vida social porque gastam todo o seu tempo, dinheiro e energia cuidando de seus animais. São emocionalmente sobrecarregados, presos à indecisão e ao senso de responsabilidade e, em alguns casos, cientes de que seu comportamento é irracional e insalubre. Entretanto, o estresse de descartar os animais é grande demais para eles resolverem a situação. Suas moradias costumam ser depauperadas, visto que a renda que possuem está quase que exclusivamente destinada aos animais. É muito comum ocorrerem problemas de saúde, tanto do acumulador quanto dos animais por ele confinados, seja por inalação de amônia oriunda do acúmulo de fezes, seja por doenças transmitidas por picada de pulgas, carrapatos ou pelo convívio com a falta de higiene. É possível que haja alguma dificuldade em processar a informação emocional em conjunto com a informação perceptiva, ou seja, que existam mecanismos fisiológicos para evitar a consciência de que estejam causando dor e sofrimento aos animais por eles cuidados $^{9,13,14,15}$

\section{Acumulação animal: um novo distúrbio psicopatológico}

Segundo Ferreira et al. ${ }^{10}$, a literatura científica ainda se apresenta exígua quanto ao quantitativo de estudos empíricos que possam auxiliar a desvelar a complexidade do transtorno de acumulação animal. No entanto, em decorrência dos achados de sua pesquisa, que contradizem a concomitância entre acumulação de objetos e de animais, e apoiada por uma revisão da literatura a respeito do tema, se faz necessário estabelecer um precedente para discussão de uma nova categoria nosográfica, propondo que o colecionismo 
de animais seja compreendido como um novo distúrbio psicopatológico, com especificidades que impliquem na distinção dessa nova condição de transtorno de acumulação ${ }^{4,9,10}$.

Ferreira et al..$^{10}$ descrevem que, de uma amostra de 33 acumuladores de animais, aproximadamente $57 \%$ dos indivíduos colecionavam concomitantemente animais e objetos inanimados, aproximadamente $73 \%$ se percebiam saudáveis, enquanto que $63 \%$ relataram algum problema de saúde. Quanto ao gênero, predominaram indivíduos do sexo feminino (73\%) e $88 \%$ se declararam divorciados, viúvos ou solteiros. Esse resultado corrobora com outros estudos, aventando-se à hipótese de que o perfil de acumulador de animais pode estar mais relacionado ao sexo feminino, à idade avançada e ao isolamento social ${ }^{7,8,9}$. Do total de indivíduos entrevistados na pesquisa ${ }^{10}, 64 \%$ eram idosos, o que vai ao encontro do DSM-5 e de outros estudos empíricos sobre o tema ${ }^{10,12}$. Essa questão suscita a hipótese de quanto mais idoso for o indivíduo, maior o número de animais acumulados e de agravamento dos sintomas, o que pode estar relacionado ao comprometimento da rede de apoio, que reforçaria a busca por animais, como em um círculo vicioso ${ }^{16}$. Quanto a renda, 76\% recebiam entre 1 e 2 salários-mínimos; tendo $61 \%$ indicado como fonte de renda o recebimento de aposentadoria ou pensão. Entretanto, a baixa renda, assim como a baixa escolaridade, podem estar relacionadas a um viés de informação, visto que os indivíduos foram recrutados por uma organização que atende primordialmente indivíduos do mais baixo estrato socioeconômico no município de Porto Alegre, Rio Grande do Sul, Brasil ${ }^{10}$. O DSM-5 indica um nível baixo de 'insight' entre os acumuladores animais, entretanto $27 \%$ dos indivíduos da amostra relatou algum tipo de dificuldade em decorrência ao comportamento acumulador ${ }^{10,12}$.

Podemos observar sutis diferenças entre um acumulador de objetos inanimados (HD) e um acumulador de animais (AH) $)^{9,10}$. O critério de obstrução da circulação é uma característica peculiar aos primeiros, visto que os animais possuem mobilidade, exceto se restringidos às gaiolas, containers, etc., e não levam a obstrução dos cômodos de um domicílio ${ }^{17}$. Quanto à questão de desengajar-se do compromisso de acumular objetos ou animais, há de se distinguir o ato de descartar objetos da doação dos animais mantidos em tutela ${ }^{10}$. Os objetos inanimados, em princípio, não necessitam de maiores atenções, enquanto que animais exigem um cuidado constante, independentemente da falta de capacidade para tal apresentada pelo acumulador. Há uma hipótese de que o ato de cuidar leve à oportunidade de criação de vínculo entre o acumulador e o animal, o que pode contribuir para que o mesmo não seja desfeito tão facilmente ${ }^{18,19}$. Os critérios do DSM-5 para HD não especificam que tipos de posses que são necessárias para este diagnóstico e, sendo os animais legalmente considerados propriedade, a acumulação desses parece se qualificar como $\mathrm{HD}$, embora essa questão ainda não esteja resolvida na literatura psiquiátrica ${ }^{9,17,20}$.
Acompanhando o raciocínio supracitado, os argumentos apresentados por Ferreira et al. ${ }^{10}$ para distinguir entre HD e AH nos parece suficientemente robustos para sugerir critérios de diagnóstico específicos para o transtorno de acumulação animal (AH), que seguem descritos: a) presença de 'insight' bom ou razoável: o indivíduo reconhece que crenças e comportamentos relacionados ao acúmulo de animais são problemáticos; b) presença de 'insight' ruim: o indivíduo percebe que crenças e comportamentos relacionados ao acúmulo de animais não são problemáticos, apesar das evidências em contrário; e c) ausência de 'insight': o indivíduo está plenamente convencido de que crenças e comportamentos relacionados ao acúmulo de animais não são problemáticos, apesar de evidências em contrário.

Compartilhando das conclusões da pesquisa empírica supraci$\operatorname{tada}^{10}$, é proposto que uma nova abordagem a respeito do transtorno de acumulação de animais possa trazer alguma visibilidade do problema, ampliando o investimento em intervenções específicas que possam dar conta dessa importante questão de saúde pública.

\section{Da teoria à prática: aspectos da intervenção em casos de acumulação de animais}

Muitas vezes o ímpeto por acumular é alimentado pela superpopulação de animais domésticos que, se não forem castrados, se reproduzem livremente nas ruas das cidades em que buscam a sobrevivência ${ }^{13,17}$. Um grande número de animais, muitas vezes doentes, moribundos ou mortos, é amontoado em áreas de convivência do acumulador e de sua família. Por vezes, excrementos recobrem pisos e paredes, criando elevadas concentrações de amônia e de contaminantes orgânicos em aerossol, que representam sérios riscos à saúde dos ocupantes ${ }^{21,22}$. Pesquisas indicam que a falta de condições sanitárias adequadas está presente na maioria dos casos de acumulação de animais, o que, associado ao grande número de animais envolvidos, eleva a probabilidade de ocorrerem transmissões de doenças zoonóticas inicialmente para os ocupantes dessas residências e, posteriormente, à comunidade ${ }^{23}$.

Pode-se até estabelecer um protocolo de intervenção institucional, cuja base de atuação deve ser comum às situações que protejam determinados aspectos básicos relacionados à saúde ou aos direitos sociais, entretanto deverá ser imprescindível uma oferta ampla de serviços, colaborando para o planejamento e a execução de uma intervenção direcionada às particularidades inerentes ao caso de acumulação em questão. Contudo, não devemos automatizar os procedimentos profissionais como se tratássemos de situações generalizadas. Cada caso deve ser minuciosamente estudado e tratado como único pelo poder público ${ }^{2,4,6,22}$.

Como exemplo da complexidade das ações a serem desenvolvidas pelo poder público, dissertaremos a respeito do sexo do acumulador. Uma revisão da literatura especializada indica que a proporção entre os sexos é relativamente uniforme para os casos 
do transtorno de acumulação de objetos, enquanto que casos de acumulação de animais são predominantemente relacionados ao sexo feminino ${ }^{24}$. Em estudo de prontuários relacionados à acumulação animal nos EUA, o sexo feminino representou de 70 a $83 \%$ da casuística apurada ${ }^{4,6,11}$.

Devemos observar também que há distinção entre quem possa ter um comportamento acumulador de animais daqueles que buscam conviver de uma forma saudável, mantendo padrões sanitários aceitáveis tanto para os animais quanto para o ambiente de convivência ${ }^{4}$. Nos EUA existe um personagem muito caricato, denominado de 'Crazy Cat Lady', que pode ser 'traduzido' como uma solitária senhora de hábitos reservados que possui um contingente razoável de gatos domésticos em sua posse ${ }^{25}$. A descrição caricata muitas vezes é confundida com o estereótipo de acumuladores de animais: pessoa do sexo feminino, idosa, solitária e de hábitos reservados que tem uma vontade incontrolável de adquirir e cuidar de animais, não sendo capaz de desfazer desses, mesmo se houver impactos negativos sobre a saúde e o bem-estar humano e animal ${ }^{26}$. Dessa forma, seria interessante o serviço de saúde local se organizar para atender uma demanda peculiar de acumuladores de animais com um olhar voltado para o gênero feminino, sem deixar de buscar o caráter integral de suas ações em saúde pública, pois as desigualdades de gênero, inclusive por conta de preconceitos socialmente construídos, tendem a aprofundar outras desigualdades sociais e todas as formas discriminatórias ${ }^{27,28,29}$.

O mesmo pode-se esperar para com os idosos, visto que no caso de condutas acumuladoras a casuística é francamente favorável aos idosos e, aparentemente, há uma relação direta entre o número de animais acumulados e o decorrer da idade do acumulador ${ }^{4,12,16}$. A Política Nacional de Saúde da Pessoa Idosa ${ }^{30}$ garante um tratamento diferenciado para grupos distintos de idosos, seja em termos etários e socioeconômicos ou local de moradia, que acarretam em demandas diferenciadas, que possuem espelhamento na formulação de políticas públicas para o segmento ${ }^{31}$.

$\mathrm{Na}$ forma da lei, todo cidadão tem assegurada a saúde física e mental ${ }^{32}$. Torna-se necessário um aporte multidisciplinar dos serviços de saúde local, assim como de estruturas de suporte - caso dos Núcleos de Apoio à Saúde da Família (NASF), Núcleos de Atenção Psicossocial (NAPS) e Centros de Atenção Psicossocial (CAPS) - para garantir ao paciente o acesso à saúde integral. $\mathrm{O}$ contexto atual da assistência psiquiátrica tem, na família, um lugar privilegiado para a prática do cuidado, sendo necessário observá-la como facilitadora no complexo processo de reinserção social do acumulador ${ }^{33,34,35}$.

A ação de agentes de promoção da saúde com interfaces multidisciplinares pode ser adotada como uma forma de reduzir os conflitos de interesse entre a sociedade e os acumuladores de animais, devendo sempre buscar contemplar a vigilância e a prevenção de doenças com uma visão do coletivo, pois dessa forma haverá oportunidade para detecção de questões que sejam relacionadas aos condicionantes ambientais da saúde. A Atenção Domiciliar (AD) é uma das ferramentas que possui condições para viabilizar processos de atenção integrais aos portadores do transtorno de acumulação, sendo importante que os profissionais da ESF estejam cientes do histórico do paciente e do seu quadro nosológico atual, fundamentando a abordagem em um tripé: identificação, proteção à saúde e articulação de rede ${ }^{36}$.

A condução dada ao caso pelo profissional de saúde passa pela verificação da suspeita ou denúncia de acumulação de animais, sendo importante a observação das condições sanitárias e higiênicas em que se encontram o possível acumulador, os animais e o ambiente em que convivem ${ }^{20,34}$. Deve atentar para o contingente populacional de animais, suas condições físicas e aparente possibilidade haver maus-tratos ${ }^{4}$. As condições da manutenção da funcionalidade relacionadas ao imóvel em questão também devem ser apreciadas $^{17,36}$. Havendo necessidade, o suporte de profissional veterinário se fará necessário para um melhor diagnóstico ambiental ${ }^{35}$.

Como os recursos disponibilizados pela ESF não contemplam todas as necessidades envolvidas em situações de acumulação de animais, são necessárias ações concomitantes de setores distintos da gestão pública em decorrência de uma articulação de rede ${ }^{36}$. Casos de acumulação de animais em grandes aglomerados populacionais trazem uma particular dificuldade, pois espaços disponíveis para albergar animais recolhidos das ações sanitárias, ou estão com lotação máxima, ou não existem ${ }^{36,37,38}$.

Deve-se recorrer a outras estruturas do poder público para dar conta de complexa logística relacionada às intervenções em questão, buscando dar uma resposta segura à sociedade. Quando há acúmulo de animais, o caso passa por uma complexidade demasiada para ser operacionalizada por uma única esfera, exigindo o suporte das Secretarias de Saúde, de Assistência Social, de Promoção e Defesa dos Animais, do Meio Ambiente, de Tráfego, da Ordem Pública e de Conservação, dependendo dos arranjos administrativos do município, além dos órgãos da Polícia do Estado e do Poder Judiciário diretamente envolvidos ${ }^{21,22,39}$.

Visto que os animais são definidos como posse, ou seja, uma propriedade individual e defendida pelas boas práticas legais, o poder público poderá requerer a tutela dos mesmos, em regime provisório, para que sejam resgatados, acolhidos, adequadamente alimentados e tratados de possíveis patologias, quando houver demandas que justifiquem tamanha mobilização $0^{20,21}$. Acrescenta-se a esse fato a necessidade de comprovar a falta de zelo pelo animal e a manutenção de uma situação correlata a maus tratos, já que podem ser reavidos pela simples interpelação jurídica da decisão pela parte interessada, por representante legal ou pela Defensoria Pública, se assim não for feito. Entretanto, é notório que, apesar de estarem vivendo em condições desfavoráveis, esses animais nutrem verdadeiro sentimento de felicidade em estarem com seu "tutor", sendo este um sentimento verdadeiro e recíproco que dificulta o êxito de uma intervenção, principalmente se mal planejada ${ }^{20,21}$. 
Um projeto terapêutico deve ser organizado, pensado para atender as necessidades do cidadão que tem o agravo, sendo importante que as ações sejam concatenadas e baseadas na realidade local, contando com suporte de equipe multidisciplinar ${ }^{34}$. As recidivas são comuns, chegando a números absolutos de $100 \%$ dos casos, se mal manejados ${ }^{15,16,17}$. Para tanto, alertam Rafael e Moraes ${ }^{36}$, a fragilidade da intervenção é algo que deve ser observado, pois é natural que ocorram lacunas referentes à comunicação entre os diversos profissionais de saúde.

\section{CONCLUSÃO}

Quando decidido pela intervenção em um caso de transtorno de acumulação de animais (AH), o poder público deve se certificar de que o processo seja seguro tanto para o cidadão que sofrerá com a ruptura de hábitos e costumes, quanto para a coletividade que o cerca. As ações devem ser concatenadas entre as diversas estruturas públicas, de forma a mitigar possível sentimento de perda e os riscos para agravamento da já alterada saúde física ou emocional dos que sofrem a intervenção, seja humana ou animal.
Também é necessário prover os agentes públicos envolvidos de ferramentas operacionais e de gestão, além do aparato legal para que possam cumprir suas tarefas de forma satisfatória, devolvendo o equilíbrio ao ambiente e a resolução das demandas da sociedade.

Os serviços de atenção primária, em conjunto com outras estruturas da rede local de saúde, devem se comprometer, por meio de ações concatenadas com familiares, sociedade e demais organizações estatais, caso do Poder Judiciário, para a construção de projetos de reinserção social, respeitando as características individuais dos sujeitos envolvidos e os princípios de cidadania, com objetivo de reduzir o estigma e promover melhor qualidade de vida aos que tem agravo em questão, se não evitando, ao menos mitigando possíveis recidivas.

Aos animais, deve ser dada uma atenção diferenciada, visto que são vítimas inocentes de um processo patológico de outrem, sendo importante que seja analisada sua capacidade física e emocional previamente às ações de remoção para que evitem maiores danos quando do contato com nova realidade, através de um novo tutor ou do contato com outros animais abrigados.

\section{REFERÊNCIAS}

1. Lozano ER, Fuillerat CO, Novaldos GB, Antón MS, Gutiérrez FG, Pérez CB. Características sociodemográficas de las personas con conducta acumuladora/trastorno por acumulación (S de Diógenes) en la ciudad de Madrid: serie de casos. Rev Asoc Esp Neuropsiq. 2014;34(124):665-81.

http://dx.doi.org/10.4321/S0211-57352014000400002

2. Bratiotis C, Schmalisch CS, Steketee G. The hoarding handbook: a guide for human service professionals. Oxford University Press, 2011.

3. Campos-Lima AL, Torres AR, Yücel M, Harrison BJ, Moll J, Ferreira $\mathrm{GM}$, et al. Hoarding pet animals in obsessive-compulsive disorder. Acta Neuropsychiatr. 2015;27(1):8-13. http://dx.doi.org/10.1017/neu.2014.29

4. Patronek GJ. Hoarding of animals: an under-recognized public health problem in a difficult-to-study population. Public Health Rep. 1999;114(1):81-7.

5. Williams B. Animal hoarding: devastating, complex, and everyone's concern. Mental Health Practice. 2014;17(6):35-9.

6. Frost RO, Steketee G, Williams L. Hoarding: a community health problem. Health Soc Care Community. 2000;8(4):229-34.

7. Frost RO, Steketee G. Stuff: compulsive hoarding and the meaning of things. New York: Houghton Mifflin Harcourt, 2011; p.118-33.

8. Patronek GJ, Nathanson JN. A theoretical perspective to inform assessment and treatment strategies for animal hoarders. Clin Psychol Rev. 2009;29(3):274-81. http://dx.doi.org/10.1016/j.cpr.2009.01.006

9. Frost RO, Patronek G, Rosenfield E. Comparision of object and animal hoarding. Depress Anxiety. 2011;28(10):885-91. http://dx.doi.org/10.1002/da.20826

10. Ferreira EA, Paloski LH, Costa DB, Fiametti VS, Oliveira CR, Argimon IIL, et al. Animal Hoarding Disorder: A new psychopathology?. Psychiatry Res. 2017;258:221-5. https://doi.org/10.1016/j.psychres.2017.08.030

11. Worth D, Beck AM. Multiple ownership of animals in New York City. Trans Stud Coll Physicians Phila. 1981;3(4):280-300.

12. American Psychiatric Association. Manual diagnóstico e estatístico de transtornos mentais: DSM-5. Porto Alegre: Artmed, 2014.

13. Cassiday KL. Animal hoarding. Disponível em: https://adaa.org/ understanding-anxiety/obsessive-compulsive-disorder-ocd/ hoarding-basics/animal-hoarding. Acesso em: 08 jan. 2019.

14. Sinclair L, Merck M, Lockwood R. Forensic investigation of animal cruelty: a guide for veterinary and law enforcement professionals. Can Vet J. 2007;48(9):941-2.

15. Berry C, Patronek G, Lockwood R. Long-term outcomes in animal hoarding cases. Animal L. 2005;11:167-94.

16. Irigaray TQ, Esteves CS, Pacheco JTB, Grassi-Oliveira R, Argimon IIL. Maus-tratos contra idosos em Porto Alegre, Rio Grande do Sul: um estudo documental. Estud Psicol. 2016;33(3):543-51. http://dx.doi.org/10.1590/1982-02752016000300017

17. Frost RO, Patronek G, Arluke A, Steketee G. The hoarding of animals: an update. Psychiatr Times. 2015;32(4).

18. Nathanson JN. Animal hoarding: slipping into the darkness of comorbid animal and self-neglect. J Elder Abus Negl. 2009;21(4):307-24

http://dx.doi.org/10.1080/08946560903004839

19. Reinisch Al. Understanding the human aspects of animal hoarding. Can Vet J. 2009;49(12):1211-14.

20. Mataix-Cols D. Hoarding disorder. N Engl J Med. 2014;370:2023-30. http://dx.doi.org/10.1056/NEJMcp1313051

21. Patronek GJ. The problem of animal hoarding. Disponível em: http://vet.tufts.edu/wp-content/uploads/municipalawyer.pdf. Acesso em: 08 jan. 2019 
22. Patronek GJ, Loar L, Nathanson JN. Animal hoarding: structuring interdisciplinary responses to help people, animals, and communities at risk. Hoarding of Animals Research Consortium. 2006.

23. Health implications of animal hoarding. Health Soc Work. 2002;27(2):125-36.

https://doi.org/10.1093/hsw/27.2.125

24. Steketee G, Frost RO. Phenomenology of hoarding. In: Frost RO, Steketee G. Handbook of hoarding and acquiring. New York: Oxford University Press, 2014; p.19-32.

25. Avery L. From helping to hoarding to hurting: when the acts of "Good Samaritans" become felony animal cruelty. Val U L Rev. 2005;39(4):815-58.

26. Svanberg I, Arluke A. The Swedish swan lady: reaction to an apparent animal hoarding case. Soc Anim. 2016;24(1):63-77. https://doi.org/10.1163/15685306-12341388

27. Herzog HA. Gender differences in human-animal interactions: A review. J Anthrozoös. 2007;20(1):7-21. https://doi.org/10.2752/089279307780216687

28. Amorim LT. Gênero: uma construção do movimento feminista? Disponível em: http://www.uel.br/eventos/gpp/pages/arquivos/ Linamar.pdf. Acesso em: 15 jan. 2019.

29. Brasil. Ministério da Saúde. Secretaria de Atenção à Saúde. Departamento de Ações Programáticas Estratégicas. Política nacional de atenção integral à saúde da mulher: princípios e diretrizes. Brasília: Ministério da Saúde, 2004.

30. Brasil. Portaria $n^{\circ}$ 2.528, de 19 de outubro de 2006. Aprova a Política Nacional de Saúde da Pessoa Idosa. Disponível em: http://bvsms.saude.gov.br/bvs/saudelegis/gm/2006/prt2528 19 10 2006.html. Acesso em: 11 jan. 2019.
31. Camarano AA, Pasinato MT. O envelhecimento populacional na agenda das políticas públicas. In: Camarano AA. Os novos idosos brasileiros: muito além dos 60. Rio de Janeiro: IPEA, 2004; p.25389.

32. Lima RSF. Direito à saúde e critérios de aplicação. Rev Direito Público. 2006;3(12):112-32. https://doi.org/10.11117/22361766.12.01.05

33. Duarte VR, Bonfim CV, Silva G, Santos LF. Acumuladores: multidiciplinaridade em ação. An Congr Bras Med Fam Comunidade. 2013;12:6

34. Araujo ENP, SantosVG. Transtorno de acumulação compulsiva de idosos: Possibilidades de cuidados e questões de saúde pública. Rev Kairós Gerontol. 2015;18(4):81-100.

35. Begali JH, Carvalho AAB. Subsídios para implantação de um Núcleo de Apoio à Saúde da Família (NASF) com inserção do médico veterinário. Dissertação (Mestrado) - Universidade Estadual Paulista. Jabuticabal: 2016.

36. Rafael ET, Moraes MCL. O comportamento de acumulação de animais e a Estratégia Saúde da Família: uma discussão introdutória. Rev Eletron Acervo Saúde. 2018;(Supl.10):918-22. https://doi.org/10.25248/REAS90 2018

37. Cunha GR, Martins CM, Ceccon-Valente MF, Silva LL, Martins FD, Floeter D, et al. Frequency and spatial distribution of animal and object hoarder behavior in Curitiba, Paraná State, Brazil. Cad Saúde Pública. 2017:33(2):e00001316. http://dx.doi.org/10.1590/0102-311×00001316

38. Costa ED, Biondo AW. Animal Abuse complaints assisted in Curitiba, Paraná, Brazil. Dissertação (Mestrado) - Universidade Federal do Paraná. Curitiba: 2016.

39. Tavolaro P, Cortez TL. A acumulação de animais e a formação de veterinários. Atas de Saúde Ambiental. 2017;5:194-211. 